\title{
Gestão de Estoques e sua Influência na Qualidade da Prestação de Serviços Hospitalares em Juazeiro do Norte-CE: um Olhar do Público Atendido
}

\author{
Rafael Costa Santos ${ }^{1}$ Alyne Leite de Oliveira ${ }^{2}$
}

\begin{abstract}
RESUMO: O presente trabalho tem por objetivo analisar a influência do gerenciamento de estoques na qualidade da prestação de serviços hospitalares em Juazeiro do Norte-CE, através de um estudo exploratório de caráter quantitativo, onde foram aplicados 400 questionários à população da cidade de Juazeiro do Norte, por critério de conveniência e acessibilidade dos mesmos. O instrumento de coleta de dados dividiu-se em quatro partes, a primeira contendo aspectos relacionados aos dados sócio demográficos, a segunda abrange aspectos relacionados a qualidade na prestação dos serviços, na terceira com aspectos relacionados à gestão de estoques e a quarta tendo como base as cinco dimensões da qualidade propostas pela escala Servqual. Os resultados obtidos demonstram peculiaridades nos serviços que precisam de melhorias e em relação da gestão dos materiais é importante o uso de ferramentas que favoreçam o gerenciamento mais efetivo, pois afetam diretamente na qualidade do atendimento e desempenho nas atividades.
\end{abstract}

Palavras chave: Qualidade. Gestão de estoques. Gestão Hospitalar.

\section{Management of Stocks and their Influence in the Quality of the Provision of Hospital Services in Juazeiro do Norte-CE: A Look of the Public Served}

\begin{abstract}
The present study has the objective of analyzing the influence of stock management on the quality of hospital services in Juazeiro do Norte - CE, through an exploratory study of a quantitative character, in which 400 questionnaires were applied to the population of the city of Juazeiro do Norte, by criteria of convenience and accessibility. The data collection instrument was divided into four parts, the first containing aspects related to socio-demographic data, the second covers aspects related to quality of service provision, the third with aspects related to inventory management and the fourth one based on data the five dimensions of quality proposed by the Servqual scale. The results obtained show peculiarities in the services that need improvements and in relation to material management, it is important to use tools that favor more effective management, as they directly affect the quality of care and performance in the activities.
\end{abstract}

Keywords: Quality. Inventory management. Hospital management.

\section{Introdução}

Os hospitais concedem serviços essenciais à sociedade de maneira que se faz importante um nível satisfatório de atendimento, para tanto é necessário atuar com profissionais motivados e capacitados, juntamente com o auxílio das suas instalações e materiais adequados, que são de

\footnotetext{
${ }^{1}$ Graduando do Curso de Administração do Centro Universitário Doutor Leão Sampaio/Unileão-rafaelcosta2018@gmail.com ${ }^{2}$ Professora Orientadora do Centro Universitário Doutor Leão Sampaio/Unileão-alineoliveira@ leaosampaio.edu.br 
fundamental importância para atingirem os objetivos estabelecidos. Desta maneira os recursos são de grande importância sua atuação da organização, dada a possibilidade de minimização dos riscos, implementação de novas tecnologias, melhorando seu desempenho, controle e fluxo de dados (BURMESTER, 2013).

Segundo Nogueira (2018), no Brasil as organizações estão se adequando e inserindo métodos para um melhor e mais eficiente gerenciamento e aperfeiçoamento dos seus diversos processos logísticos. O desempenho dos estoques e sua aplicação no processo do controle dos materiais vem se tornando um enfoque fundamental para a organização, onde por sua vez poderá gerar benefícios como redução custos, melhoria na rentabilidade, mantendo um maior controle e assim agregando valor e influenciando na tomada de decisões, bem como garantir o nível de qualidade desejado ao produto serviço que for disponibilizado.

Os aspectos mencionados contribuem não apenas para gerar competitividade entre as organizações, mas para garantir a manutenção da mesma a partir do atendimento das demandas vigentes. Contudo, uma má gestão pode acarretar problemas na falta de materiais significativos, perda de tempo ou com altos níveis de estoque, assim deixando imobilizado parte do capital investido, ou mesmo altos custos de falta e de oportunidade (NOGUEIRA, 2018).

Tendo em vista que os recursos são constantemente onerosos para as organizações, percebe-se a necessidade de compreender cada um desses recursos para o processo produtivo e melhoria nos serviços, desse modo questiona-se qual a percepção da população da cidade de Juazeiro do Norte quanto à acurácia dos atendimentos dado o nível de gerenciamento de materiais hospitalares?

O trabalho desse modo tem por objetivo analisar a percepção de usuários de serviços hospitalares de Juazeiro do Norte-CE, acerca da influência do gerenciamento dos estoques na qualidade da prestação de serviços. Para o alcance do objetivo proposto, se faz relevante discutir acerca da influência da gestão de materiais para o desempenho organizacional, bem como verificar se o gerenciamento destes influência na percepção da qualidade percebida pelos consumidores

Visto que a atuação dos gestores requer um conhecimento dos recursos organizacionais, pois afetam diretamente nos resultados e objetivos, contribuindo para obter melhores decisões, maximizando processos e minimizando perdas, este estudo além de apresentar o cenário que norteia o gerenciamento de estoques, pode contribuir com informações de qualidade para as organizações a partir da apresentação dos dados, métodos e técnicas que favoreçam a tomada de decisões efetivas. 


\section{Gestão de Recursos Materiais}

A gestão dos recursos materiais é uma das principais atividades do processo logístico. Este trabalho adentra essa área discutindo a mesma como fator fundamental para à garantia da qualidade dos serviços prestados. Desse modo, se faz importante compreender como se desenha a área.

A logística se tornou um fator importante, sendo sinônimo de movimentação de bens, cargas, pessoas e armamentos, como na segunda guerra mundial, planejando os suprimentos de forma controlada para atender as necessidades, com o avanço da tecnologia e as exigências do mercado, se adaptando a cada época (GONÇALVES, 2013).

Segundo Dias (2017), pode ser descrita com o objetivo de compreender de forma planejada, controlada, coordenada e executada a movimentação dos recursos, com o propósito de gerar o máximo de eficiência no transporte e armazenagem, interagindo na administração de maneira que desenvolvam as atividades e melhorando os processos. A atuação logística agrega valor, gerando uma maior competitividade, desenvolvimento, controle nos processos e recursos, atendendo as exigências com um melhor fluxo e serviço (CORONADO. 2013).

Pozo (2015) descreve que existem três atividades primárias essenciais ao desenvolvimento do processo: transporte, manutenção dos estoques e processamento de pedidos. E seis atividades que dão suporte, como manuseio dos materiais, armazenagem, embalagem, suprimentos, planejamento e o sistema de informação. As práticas exercidas tradicionalmente com os canais de distribuição evoluíram ao longo do tempo, assim os bens e serviços com mais opções e variedades para os consumidores conotando especificidades mais individuais e tendo sistemas para seu auxilio de informações aperfeiçoando suas atividades (BOWERSOX et al., 2014).

De acordo com Dias (2017) a gestão dos estoques viabiliza a minimização dos recursos investidos, maximizando os resultados nos processos de produção. Para Gonçalves (2013), os estoques detêm aspectos que interligam os processos que da empresa para atender a demanda, assim planejando suas compras através de lotes, com previsões de dados obtidos, levando em consideração os prazos e exigências estabelecidas pelo cliente.

Dias (2017) destaca que para se obter um maior controle e organização, se faz necessário definir o que se encontrará nos estoques e suas quantidades, como também seu ciclo ou fluxo de reposição de materiais com suas respectivas demandas nos prazos adequados, solicitando ao setor a obtenção de mercadorias, e assim buscando um controle em números de bens e preços, com atenção as entradas, armazenagem e distribuição nos modelos ou critérios da 
organização, repassando os dados importantes para sua administração fazendo checagens pontualmente e observando a situação física das matérias, caso ocorra algum desgaste, defeito ou envelhecimento será feito o recolhimento dos mesmos.

Nogueira (2012) menciona que a previsão de vendas se inicia partir das entradas de insumos na organização, considerando quais produtos serão desenvolvidos, suas quantidades e seu prazo para a entrega. Citando também sobre a carteira de pedidos onde são pedidos sobe encomendas.

Satisfazer os clientes sempre vai ser o foco de toda organização, seja de bens ou serviços e a empresa, por sua vez, possui suas estratégias, que não se inclui apenas a qualidade de seu produto, mas em especial o treinamento e qualificação adequada de seus colaboradores. Sendo assim necessária uma preocupação por parte da organização ter um bom planejamento, buscando o aperfeiçoamento constante de seus processos diante de tantas mudanças no mercado. $\mathrm{O}$ autor cita também que se deve estabelecer uma relação de parceria entre o consumidor, fornecedor e comerciante, levando em consideração o desempenho como um todo na atuação logística, sendo profissional e ético (LAS CASAS, 2012).

Para um melhor gerenciamento dos recursos materiais existem ferramentas que proporcionam um maior controle das atividades, tais como: Métodos de Previsão de Demanda (Método do Último Período, Média aritmética, Ponderada, com suavização exponencial e dos mínimos quadrados); Estoques de Segurança; Custos de armazenagem; Métodos de avaliação de estoques (PEPS, UEPS ${ }^{3}$ e Custo médio); administração de produção (Just in Time, Material requiriment planning_MRP); administração de compras (Manufactoring resource planning_MRP II, Lote econômico de compras _LEC, Kanban); Curva ABC, etc (POZO, 2008).

Todas essas ferramentas e métodos, se bem utilizados, podem contribuir o bom gerenciamento dos materiais necessários ao desempenho das atividades da empresa, que não vai incorrer em custos de falta ou de excesso do material. Consequentemente irá garantir o atendimento no tempo, lugar e quantidade requeridos pelo consumidor, satisfazendo assim as suas necessidades e favorecendo o nível de serviço determinado.

${ }^{3}$ PEPS (Primeiro que entra é o primeiro que sai), UEPS (Último que entra é o primeiro que sai. 


\section{Qualidade: Conceito, características e abordagem na prestação de serviços}

De acordo com Carpinetti (2016) o conceito de qualidade se constitui de maneiras diversas em meio a população em conjunto com outros vocábulos como competitividade, produtividade, eficiência e integração. É comum se observar a qualidade alocada a características intrínsecas de excelência de bem, assim a qualidade se interliga a necessidade dos consumidores em questão da adaptação do determinado produto no que refere a sua utilidade, dado o nível de satisfação das necessidades do usuário no momento da sua utilização.

Sua evolução teve início antes de 1920, onde só eram checados a qualidade do produto após o mesmo estar concluído, ou melhor, com controle e verificaçoes ao seu término. Com o passar do tempo e sua evolução houve o desenvolvimento de quatro fases ou eras da qualidade, segunto Toledo et al. (2017), assim denominadas: Era da Inspeção, do Controle Estatístico, da garantia da Qualidade e do Controle da Qualidade Total (TQM)

Juran e DeFeo (2015) destacam que a gestão da qualidade pode gerar benefícios para as organizações e uma maior participação no mercado, tendo em vista que deve se constituir pela satisfação do cliente, fundamentando-se nos seus anseios e vantagens que o produto se dispõe. Com melhoria contínua, gerando um maior desempenho em termos de processos, produtos ou serviços, afetando assim as receitas e os custos, haverá um maior controle, e um produto com um nível satisfatório que poderá fidelizar os clientes, com isso uma maior receita e crescimento para a organização.

Para efetividade da gestão da qualidade, esta pode ser realizada a partir do uso de ferramentas, dentre elas destaca-se o ciclo PDCA (RENÓ, 2013)

$\mathbf{P}=$ Planejar corresponde ao fazer o planejamento trabalhos anteriormente a sua execução, com a maneira que deve realizada e até onde o objetivo foi estabelecido;

$\mathbf{D}=$ Desenvolver mostra-se o processamento das atividades, com controle das informações para seu gerenciamento futuro;

$\mathbf{C}=$ Controlar se faz o acompanhamento das atividades e de suas conclusões, onde a confrontação do planejado com o foi alçando e também e se há algumas discrepâncias ou impasses obtidos;

$\mathbf{A}=$ Agir são as proposta de melhoramento constante para as dificuldades nos procedimentos.

Montgomery (2017) descreve que há quatro custos com a gestão da qualidade sendo: custos de prevenção em aspectos ligados no processo de projetos e desenvolvimento dos produtos da forma correta na primeira vez, onde buscam a resguardar imperfeições; os custos 
de avaliação, como o próprio nome já menciona, tem o objetivo de medida, auditoria de produtos, avaliação de matérias e utensílios com os padrões inseridos, como condições de adequações para organizações garantindo uma melhor qualidade com inspeções e manutenção; os custos com falhas internas, estão diretamente atado com os materiais, itens ou serviços, que não estão adequados, também sendo descoberto antes da entrega ao cliente; e por fim os custos associados as falhas externas, que correspondem aos produtos que não satisfizeram as necessidades do consumidores.

Desse modo, é importante não apenas o conhecimento dos custos associados, mas principalmente a minimização destes seja por onerar o orçamento da empresa ou por contribuir para a insatisfação do cliente ou consumidor, devido à ineficiência deles decorrentes.

\section{Qualidade na Prestação de Serviço}

Toledo et al (2017) citam que os serviços podem ser descritos como quaisquer trabalhos exercidos por uma pessoa tendo em vista beneficiar outras, contendo características especificas. É importante ter visão holística e sistemática com um maior rigor, com a inclusão de detalhes para não só compreender o cliente, mas o serviço como um todo (ZEITHAML; PARASURAMAN; BERRY, 2014).

Os serviços, diferentemente do produto acabado, tem aspectos que só quem recebe vai poder descrevê-las associando à nível de excelência ou não, visto que ele conta com características descritas a seguir:

Quadro 2: Características dos serviços

\begin{tabular}{|c|l|}
\hline Intangibilidade & $\begin{array}{l}\text { Pode ser descrito por uma experiência, onde não pode ser mensurado antes } \\
\text { da compra, pois não há o contato, nem cheiro, ouvido ou experimentado. }\end{array}$ \\
\hline $\begin{array}{c}\text { Inseparabilidade ou } \\
\text { Simultaneidade }\end{array}$ & $\begin{array}{l}\text { Descreve como sendo o processo de produção até o consumo do cliente, } \\
\text { com isso ele inicia e a prestação de serviços se tornando importante para o } \\
\text { sistema de operações e qualidade. }\end{array}$ \\
\hline Heterogeneidade & $\begin{array}{l}\text { Fala em variáveis de serviços, onde são executadas de acordo com cada } \\
\text { pessoa e podem ser afetas pelas tecnologias atuais, tendo como variações } \\
\text { o tempo, ambiente, fornecimento de bens e as pessoas, }\end{array}$ \\
\hline Perecibilidade & $\begin{array}{l}\text { Se mostra como um serviço incapaz de ser armazenado, pois deve ser } \\
\text { constituído no momento da prestação de serviço, adequando sua } \\
\text { capacidade de produção com pessoas, maquinários e instalações } \\
\text { organizacionais. }\end{array}$ \\
\hline
\end{tabular}

Fonte: Adaptado Toledo et al (2017) 
Observa-se então que o serviço não pode ser estocado, é perecível, é heterogêneo e inseparável, no entanto para que ele ocorra em nível de excelência se faz necessário uma gama de aparatos matérias para lhe dar suporte.

A acurácia dos estoques, que são a disponibilidade dos equipamentos ou materiais prontos para o atendimento, se constitui de fundamental importância nas atividades prestadas, pois mostra se há discrepância em relação dos estoques atuais e os contabilizados, indicador este que determina o grau de comprometimento dos exercícios do processo de entrada, armazenagem e controle das saídas feitas pelas pessoas responsáveis, causando insatisfação ou não em decorrência do grau de atendimento. Existem componentes deste sistema que devem ser considerados, como a previsão de demandas, realocação dos bens, escolha dos fornecedores, para obter maior pontualidade, sendo eficiente na colocação dos pedidos nas quantidades certas e com isso atendendo as exigências estipuladas, garantindo a qualidade nos serviços prestados (BARBIERI; MACHLINE, 2017).

Para mensurar o grau de atendimento dos serviços, utiliza-se a ferramenta Servqual que, de acordo com Gianesi e Corrêa (2012) se caracteriza como um instrumento de medição da qualidade dos serviços prestados, com dimensões de avaliações para medir as percepções do desempenho do serviço, baseando-se em critérios a serem observados como a:

- Confiabilidade se caracterizando pela capacidade de prestar serviços de maneira segura, estável e continuo;

- Responsividade se mostra como a coordenação dos serviços a serem de prestados de forma imediata e que contribuem para as pessoas;

- Confiança pode ser descrito como as habilidades concernentes a cada pessoa e as atitudes em prol de disseminar firmeza, garantia e confiabilidade do serviço;

- Empatia sendo a concentração individual a cada pessoa de forma simples, agradável, com intuito de melhor as informações e obter uma boa convivência, e;

- Tangíveis se mostram como todos os bens comunicação de informações, materiais, pessoas da organização e sua estruturas e instalações que facilitem o serviço.

Assim se torna um instrumento importante, pois observam de forma abrangente os critérios e auxiliam desta maneira nas decisões administrativas e atitudes posteriores, agregando valor, sendo mais competitiva e buscando uma maior qualidade na prestação de serviços.

O instrumento conta com cinco dimensões onde cada variável poderá retratar valores baixos, regulares ou altos, em geral números de 0 a 10, onde pode ter impactos na melhoria dos serviços com os dados adquiridos, aumentando sua competitividade, se destacando por uma 
excelência nos serviços prestados, acarretando em fidelização, conhecimento da organização pelos clientes e maior rentabilidade e satisfação (ZEITHAML; PARASURAMAN; BERRY, 2014).

\section{Gestão de Recursos Hospitalares para a Garantia da Qualidade dos Serviços Prestados}

Segundo Bumester (2013) no ambiente hospitalar há uma variedade de serviços ofertados, tais como consultas médicas, exames, cirurgias, dentre outros. A plena execução destes depende de fatores que vão desde a compra de maquinário e utensílios (balanças, móveis, respiradores, medicamentos, ambulâncias, instrumentos cirúrgicos, instalações, gases, filtros, tanques, etc citados por Barbieri e Machline, 2017) até o material de limpeza do uso diário (utensílios de limpeza, lavanderia) para atendimentos a população.

A eficiência é algo indispensável seja em qual for o seu ramo, e quando se trata de uma boa avaliação, armazenamentos, compras, atendimento e entrega de produtos ou serviço em uma empresa, logo se pensa em logística, na relação interna e externa onde busca o máximo de economia e qualidade, sendo uma meta para as empresas, a redução de custos, rapidez, segurança e assim atuando em diversos setores e interligando-os (CARPINETTI, 2016).

Assim é imprescindível o desenvolvimento de projetos, visando a gerencia na qualidade dos processos, com criatividade, liderança das pessoas, atitudes e melhores práticas para atingir os resultados propostos, com aperfeiçoamento e acompanhamento para reduzir as causas das falhas que possam ocorrer ou que estejam no processo (MENEZES, 2015).

Segundo Gonçalves (2006, p. 12) “O gerenciamento na área da saúde é mais complexo do que em qualquer outro tipo de organização. A qualidade passou a ser condição essencial para a sobrevivência de um serviço, não se trata de uma meta a ser cumprida, mas de uma condição básica a ser observada.

\section{Método}

Foi realizada uma pesquisa exploratória, onde segundo Lakatos; Marconi (2017) e Gil (2017) mencionam como investigações empíricas, contendo objetivos de conhecer, desenvolver hipóteses e obter mais informações sobre ambiente, problema ou fenômeno, com procedimentos sistemáticos ou observações práticas. Contendo uma abordagem quantitativa, 
sendo de natureza básica, onde Gil (2017) descreve como uma forma de aperfeiçoar a pesquisa com diferentes maneiras de respaldar os resultados adquiridos colaborando com o estudo.

A pesquisa foi feita com a população localizada no Juazeiro do Norte-CE, onde a cidade é composta por uma população de aproximadamente 270.383 pessoas, tornando-se a terceira mais populosa do Ceará (IBGE, 2017).

Assim foi aplicado um questionário de 16 perguntas acrescentando a análise parcial das variáveis do Servqual, buscando identificar e analisar a percepção e influência do gerenciamento dos estoques na qualidade da prestação a população. As questões foram apresentadas por meio da estatística descritiva, com uso do excell. Foram aplicados 400 questionários, utilizando-se de formulários impressos ou por meio da plataforma google forms.

É importante destacar que o instrumento dividiu-se em quatro partes, a primeira contendo aspectos relacionados aos dados sócio demográficos, segunda abrange aspectos relacionados a qualidade na prestação dos serviços, na terceira com aspectos de gestão de estoques e a quarta tendo como base parcial as cinco dimensões da qualidade.

\section{Análise e Discussão dos Resultados}

$\mathrm{Na}$ etapa referente a dados sócio demográficos, o público investigado caracterizou-se em: $61 \%$ feminino e $39 \%$ masculino; $73,50 \%$ entre 18 a 30 anos, $24,50 \%$ de 31 a 59 anos e acima de 60 anos 2\%; com grau de escolaridade $49 \%$ pessoas com ensino superior incompleto, $8 \%$ com já formados, $21 \%$ ensino médio completo, $12 \%$ ensino médio incompleto, $2 \%$ com ensino fundamental completo e $8 \%$ incompleto.

No tocante à qualidade na prestação do serviço obteve-se que há uma maior concentração na necessidade de atendimentos por meio de consultas diversas e exames $(30 \%$ e $31 \%$ ), embora os mesmos se utilizem-se de diversas outras atividades, conforme apresentado no gráfico, caracterizando o que menciona Bumester (2013). 
Gráfico 1: Você já precisou realizar algum atendimento hospitalar? Qual?

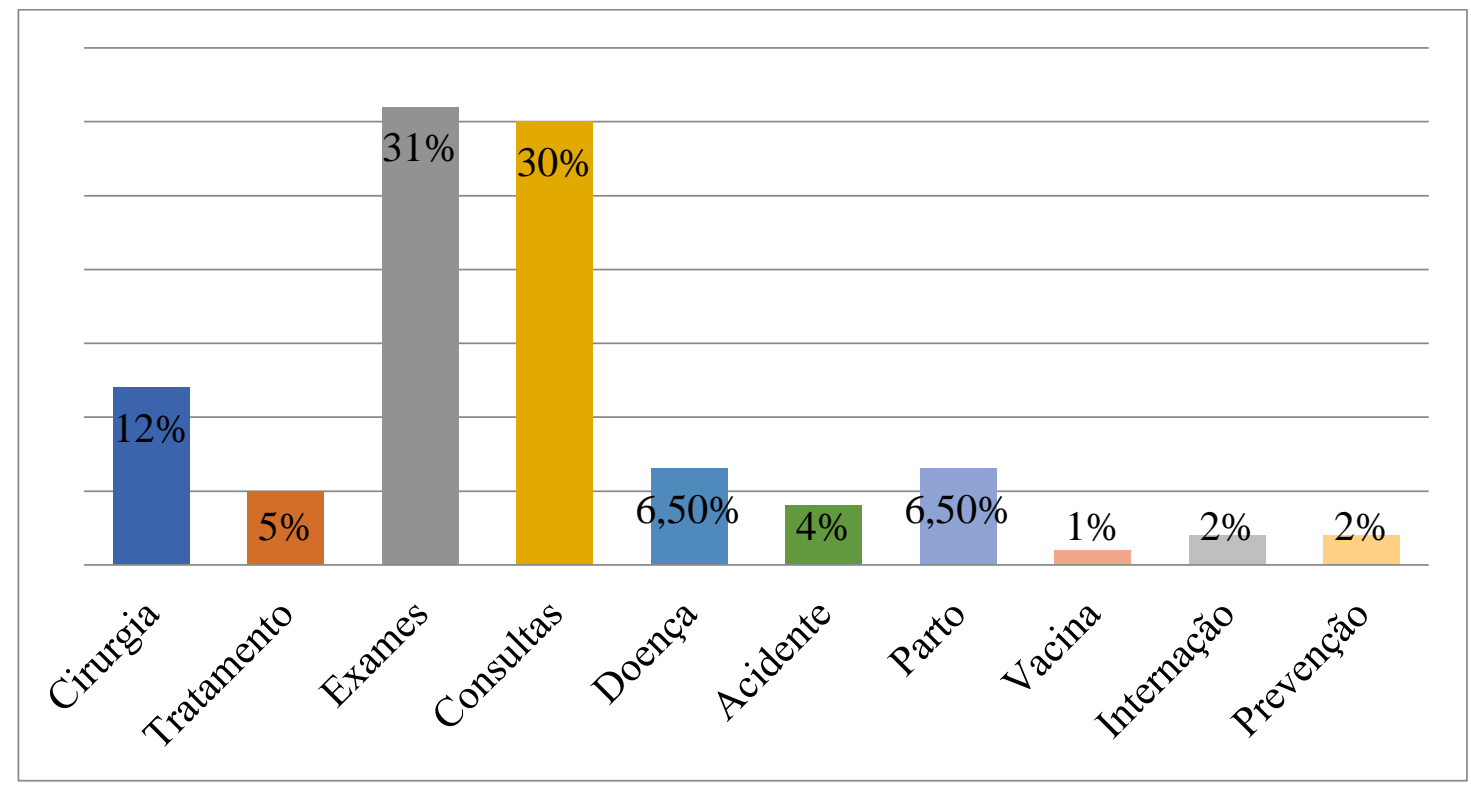

Fonte: Dados da pesquisa (2018).

Quanto à frequência de utilização dos serviços hospitalares, observa-se uma incidência que varia entre uma e três vezes ao ano $(28 \%, 26 \%$ e $14,5 \%)$.

Gráfico 2: Qual a frequência?

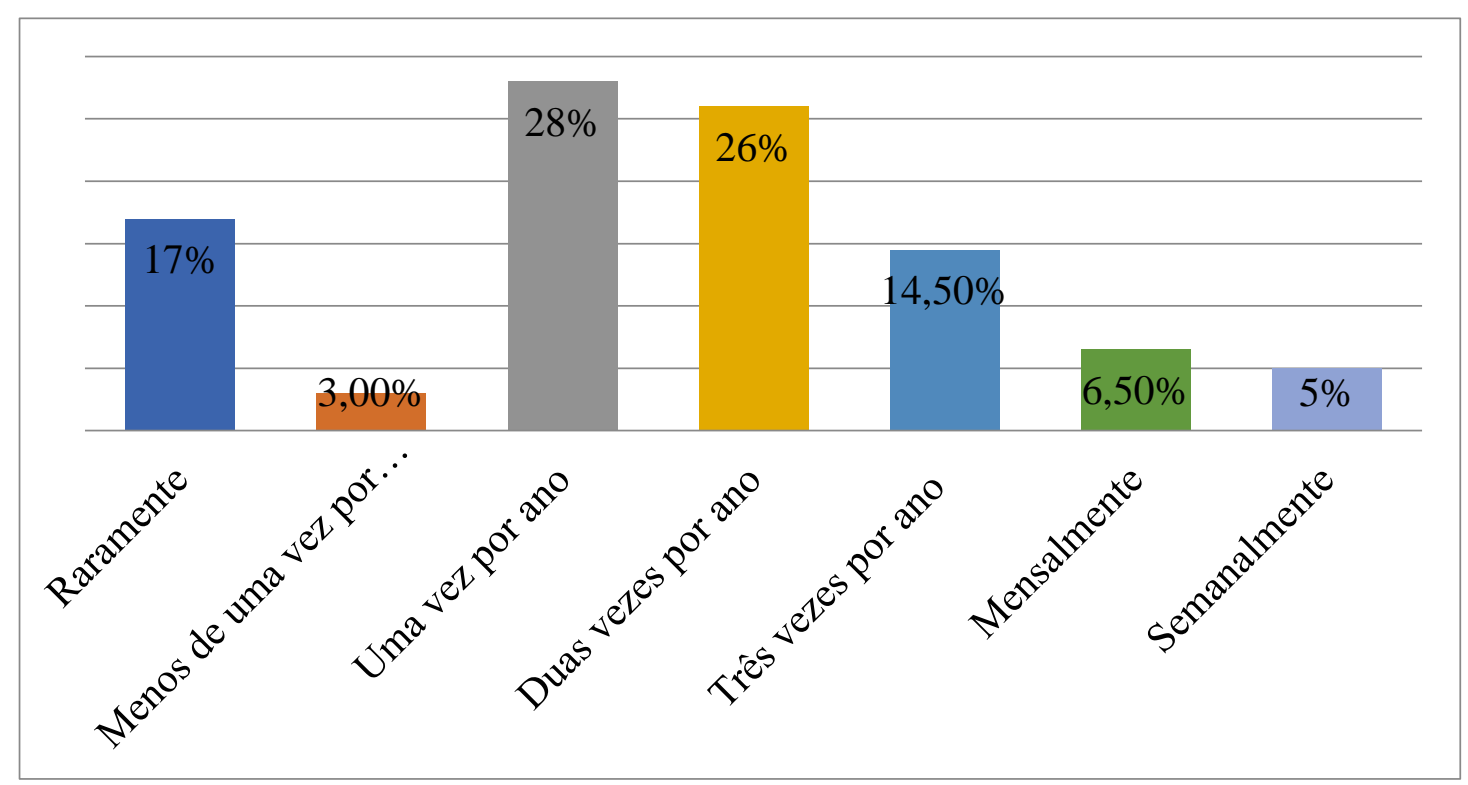

Fonte: Dados da pesquisa (2018).

Outro aspecto destacado também foi a incidência na utilização de ambientes públicos ou privados, onde se observou a predominância com $81 \%$ para unidades públicas e $19 \%$ unidades privadas. 
Gráfico 3: Quanto tempo de espera você demorou a ser atendido por falta de materiais?

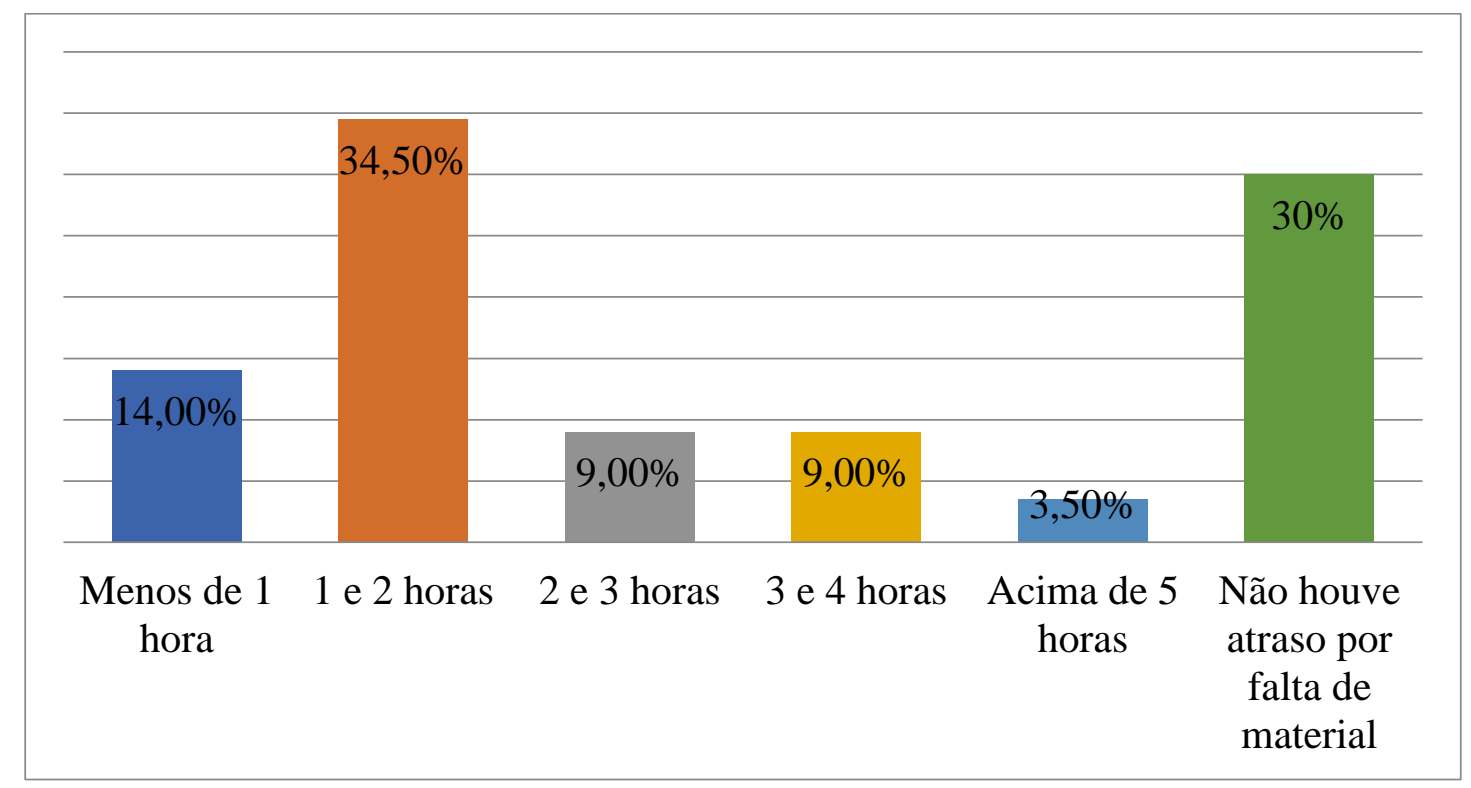

Fonte: Dados da pesquisa (2018).

Ao se abordar o tempo de espera para a ocorrência de um atendimento, tem-se $34,50 \%$ entre 1 e 2 horas para serem atendidas, $14 \%$ menos de 1 hora, e embora surjam dados de atrasos superiores a esses, percebe-se um dado importante e que deveria ser comum, de $30 \%$ que destacam a não existência de atrasos por falta de material, esse dado implica no que Nogueira (2012) menciona, que o gerenciamento das atividades se torna um fator importante para a prestação de serviços em aspectos logísticos para satisfazer os desejos dos cliente.

Ao se questionar quais procedimentos ficaram pendentes por falta de material, observase que com $78 \%$ das pessoas foram realizados o serviço prontamente e $22 \%$ ficaram pendente por falta de materiais. Embora o número de atendimentos executados prontamente tem sido bem relevantes, o que se sobressai é a incidência de $22 \%$ de atendimentos fragilizados por má gestão de recursos, o que compromete significativamente a percepção de qualidade e o nível de satisfação do consumidor, principalmente no tocante à serviços hospitalares que requer um rigor maior, dada a exigência do contexto. Esse aspecto requer o que sugere Zeithaml, Parasuraman; Berry (2014) no tocante a necessidade planejamento para que não haja a ausência dos materiais necessários. 
Gráfico 4: Qual material faltou?

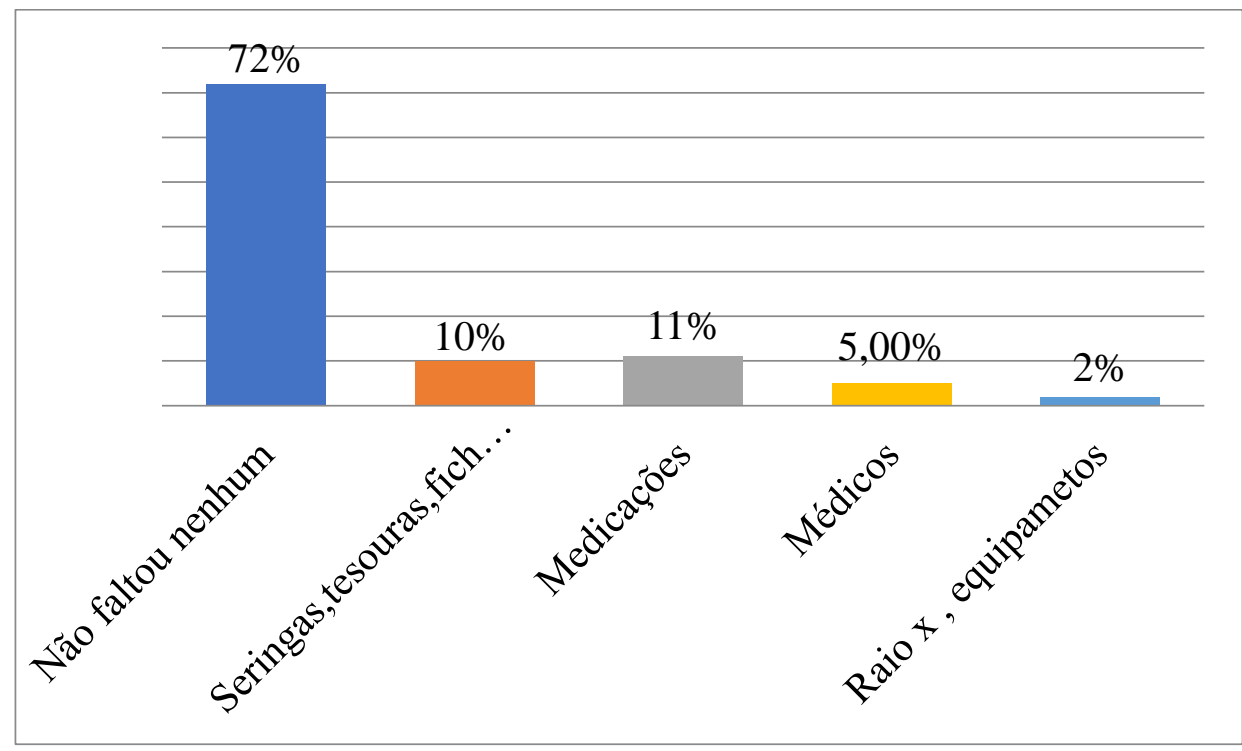

Fonte: Dados da pesquisa (2018)

Observa-se no gráfico quarto, $72 \%$ das resoluções evidenciaram que não faltou nenhum material, $10 \%$ mencionaram a ausência de seringas, tesouras, fichas, $11 \%$ a insuficiência nas medicações, $5 \%$ a escassez de médicos e $2 \%$ necessidade de equipamentos. Os bens são importantes para a prestação de serviço Barbieri e Machline (2017), com intuito de reduzir falhas, perdas ou falta de recursos (MENEZES, 2015).

Grafico 5: Como foi resolvido?

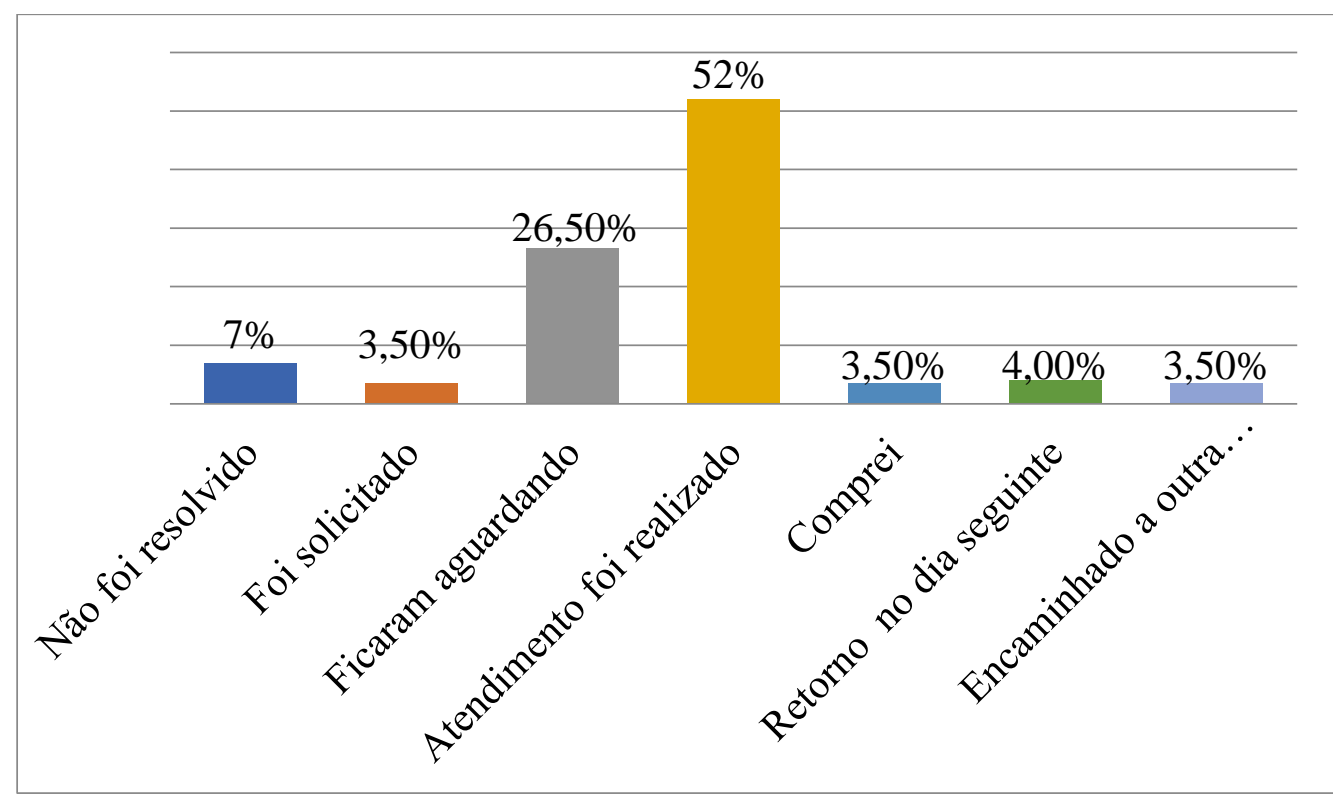

Fonte: Dados da pesquisa 2018 
Ao se questionar como se deu a resolução quanto à ausência de materiais, destaca-se que $26,5 \%$ ficaram esperando para serem atendidas, $7 \%$ que não foi resolvido, $4 \%$ retornaram no dia seguinte, $3,50 \%$ responderam que foi solicitado o material, também 3,50\% que o próprio cliente foi comprar e 3,50\% conduziram a outra unidade. Dias (2017) é enfático quando remete à necessidade de controle dos materiais observando o tempo de reposição e previsões de demandas.

Gráfico 6: Você acredita que a falta ocorreu por má gestão ou falta de investimento?

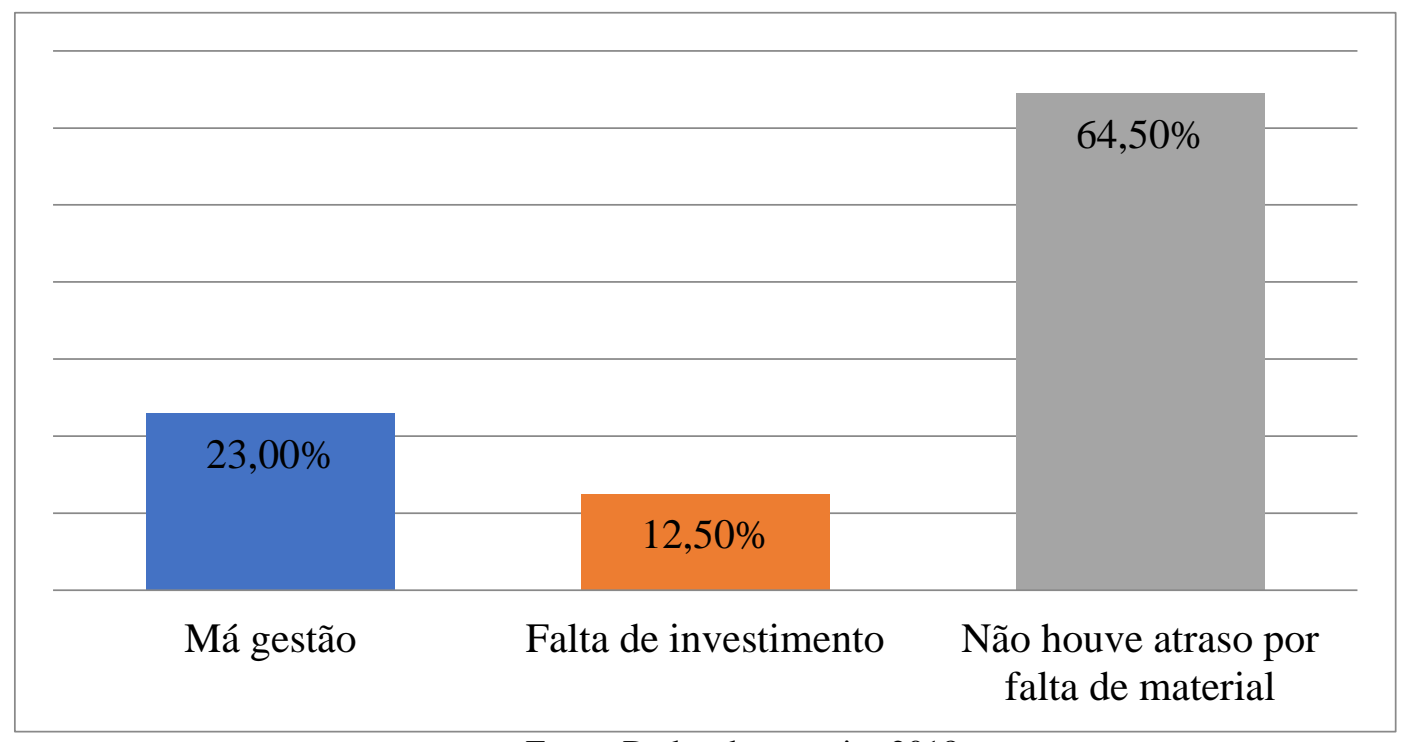

Fonte: Dados da pesquisa 2018

Visto que houve uma incidência de falhas no atendimento por falta de material e em consonância ao objetivo proposto, trabalha-se principalmente em cima desse indicador para analisar a influência de gestão de materiais para a satisfação do consumidor no quesito atendimento às suas necessidades. Desse modo, os dados acima apresentados apontam que, na percepção dos participantes, a ocorrência se dá principalmente por má gestão (23\%) e 12,50\% a falta de investimento. Montgomery (2017) destaca que a má gestão implica em custos que vão comprometer o andamento do processo, o que deve chamar a atenção dos responsáveis pelos processos em questão. 
Gráfico 7: Em sua opinião, qual o nível de qualidade do atendimento hospitalar?

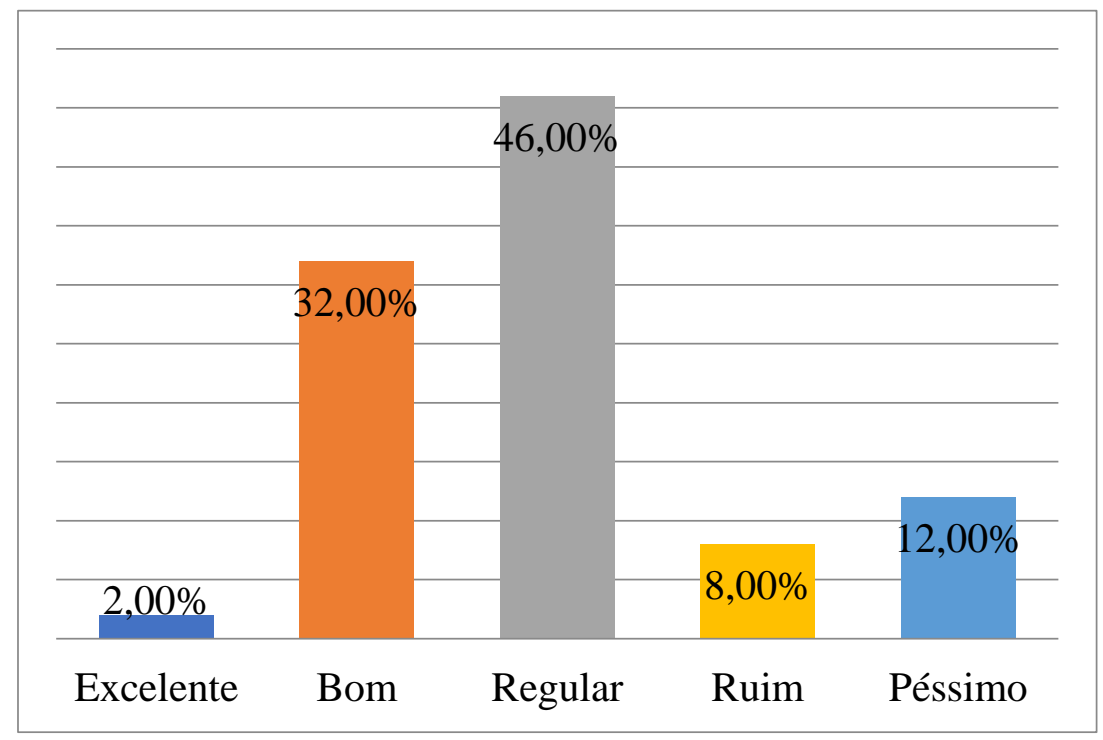

Fonte: Dados da pesquisa 2018

É notório que os custos da falta ou do excesso de material vão comprometer a percepção de satisfação do consumidor, o que é demonstrado no gráfico acima, onde, mesmo com os destaques menores para as ausências de materiais, a percepção de qualidade em $46 \%$ regular, $8 \%$ ruim e $12 \%$ péssimo. Galvão e Silva (2014) citam que para se possuir uma melhor qualidade deve-se haver um gerenciamento das pessoas, processos e materiais, tendo em vista que as habilidades e atitudes dos colaboradores na prestação dos serviços estão ligadas diretamente ao resultado final.

A terceira etapa que abordava aspectos relativos à gestão de estoques, trata da percepção do público investigado sobre a influência do mesmo no tocante ao atendimento, onde $94 \%$ destaca como muito importante.

Gráfico 8: Qual a importância que você atribui a gestão dos materiais?

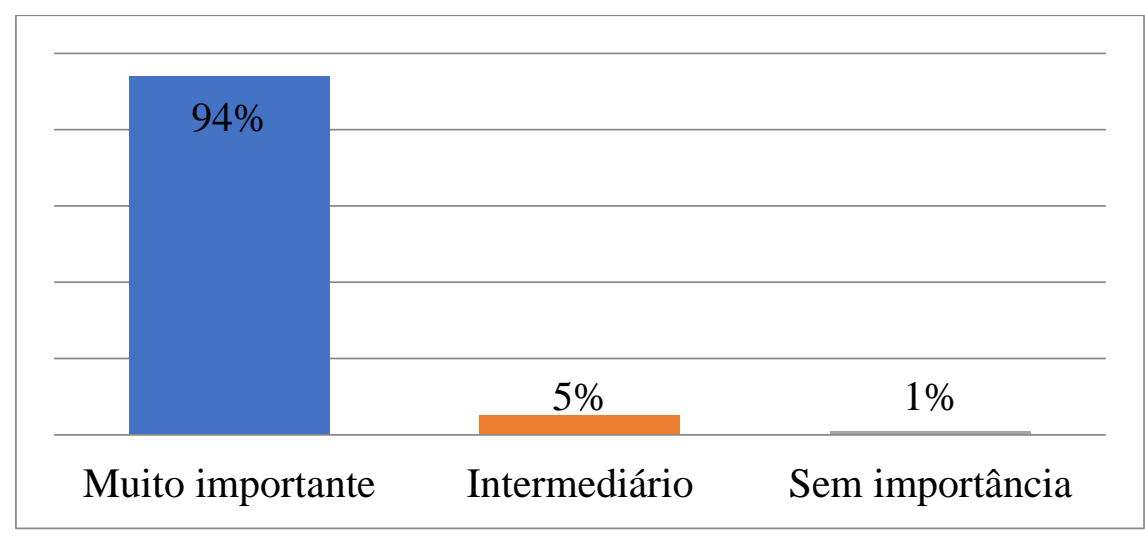

Fonte: Dados da pesquisa 2018 
O aspecto acima mencionado confirma o que é apresentado por Pozo (2008) no tocante ao uso de ferramentas para o gerenciamento dos recursos materiais, Juran e DeFeo (2015) citam vantagens competitivas, Dias (2017) processos eficientes e Coronado (2013), um melhor desenvolvimento e serviço.

Gráfico 9: Compõe as questões 14,15 e 16

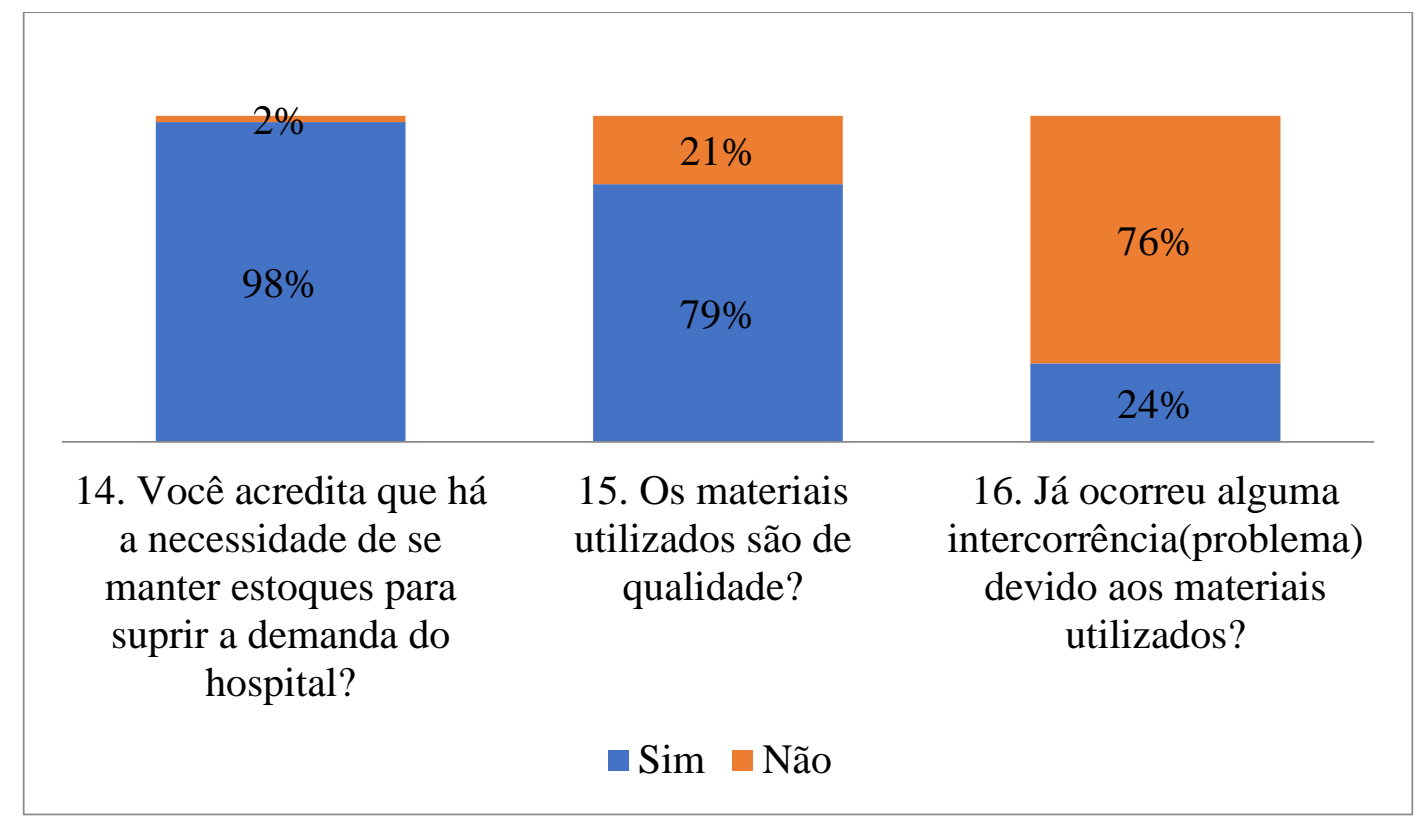

Fonte: Dados da pesquisa 2018

O gráfico nove, composto por três questões, aponta que $98 \%$ dos investigados acreditam que há a necessidade de se manter estoque para suprir a demanda do hospital e que, quando utilizados, estes são de qualidade (79\%), porém 24\% citam a existência de alguma intercorrência nesse processo, aspecto esse que vai de encontro ao que mencionam Carpineti (2016) e Juran e Defeo (2015).

Com vistas a analisar os aspectos relativos à qualidade dos serviços recebidos, e utilizando-se de uma adaptação parcial do instrumento Servqual proposto por Parasuraman, Zeitthaml e Berry (1985), foram observados critérios desde insatisfatório até extremamente satisfatório, perpassando aspectos ligados a tangibilidade, confiabilidade, resposta, garantia e empatia. 
Gráfico 10: Tangíveis

\begin{tabular}{|c|c|c|c|c|}
\hline $4,0 \%$ & $14,5 \%$ & $35,5 \%$ & $38,0 \%$ & $8,0 \%$ \\
$2,0 \%$ & $24,5 \%$ & $40,0 \%$ & $25,5 \%$ & $8,0 \%$ \\
$3,5 \%$ & $22,5 \%$ & $31,0 \%$ & $31,0 \%$ & $12,0 \%$ \\
$1,0 \%$ & $12,5 \%$ & $34,5 \%$ & $41,0 \%$ & $11,0 \%$ \\
\hline Insatisfatório & $\begin{array}{c}\text { Pouco } \\
\text { satisfatório }\end{array}$ & Satisfatório & $\begin{array}{c}\text { Muito } \\
\text { satisfatório }\end{array}$ & $\begin{array}{c}\text { Extremamente } \\
\text { satisfatório }\end{array}$ \\
& 4 Papéis e materiais de apoio com apelo visual \\
& 3 Funcionários com aparência asseada & \\
& 2 Instalações Físicas com visual atraente \\
& 1 Equipamento de visual moderno & \\
&
\end{tabular}

Fonte: Dados da pesquisa 2018

No tocante aos elementos tangíveis da área de materiais destaca-se alto nível de satisfação em todos os aspectos, embora surjam algumas percepções que remetam a insatisfação, o que requer atenção ao que destacam Barbieri e Machline (2017).

Gráfico 11: Confiabilidade

\begin{tabular}{|c|c|c|c|c|}
\hline $\begin{array}{l}4,5 \% \\
5,5 \% \\
5,5 \% \\
9,0 \%\end{array}$ & $\begin{array}{l}16,5 \% \\
26,5 \% \\
15,0 \% \\
20,0 \% \\
26,5 \%\end{array}$ & $\begin{array}{l}40,0 \% \\
41,0 \% \\
41,0 \% \\
51,0 \% \\
40,0 \%\end{array}$ & $\begin{array}{c}34 \% \\
24,5 \% \\
33 \% \\
18 \% \\
21 \%\end{array}$ & $\begin{array}{l}5,9 \% \\
9,0 \% \\
5,5 \% \\
3,5 \%\end{array}$ \\
\hline Insatisfatório & $\begin{array}{c}\text { Pouco } \\
\text { satisfatório }\end{array}$ & Satisfatório & $\begin{array}{c}\text { Muito } \\
\text { satisfatório }\end{array}$ & $\begin{array}{l}\text { Extremamente } \\
\text { satisfatório }\end{array}$ \\
\hline \multicolumn{5}{|c|}{9 Insistir em registros sem erros } \\
\hline \multicolumn{5}{|c|}{8 Realizar serviço no prazo acertado } \\
\hline \multicolumn{5}{|c|}{7 Serviços realizados certos da primeira vez } \\
\hline \multicolumn{5}{|c|}{ — 6 Interesse sincero na solução dos problemas } \\
\hline & \multicolumn{4}{|c|}{5 Realizar as Promessas no prazo acordado } \\
\hline
\end{tabular}

Fonte: Dados da pesquisa (2018).

Na confiabilidade, os dados também se apresentam satisfatórias, ainda que da incidência de insatisfação por parte de alguns. Esses dados de insatisfação podem ter partido daqueles que 
mencionaram ausência ou não atendimento por falta de material, reiterando os desafios para se obter nível melhor qualidade enfatizados por Zeithaml, Parasuraman e Berry (2014).

Gráfico 12: Resposta

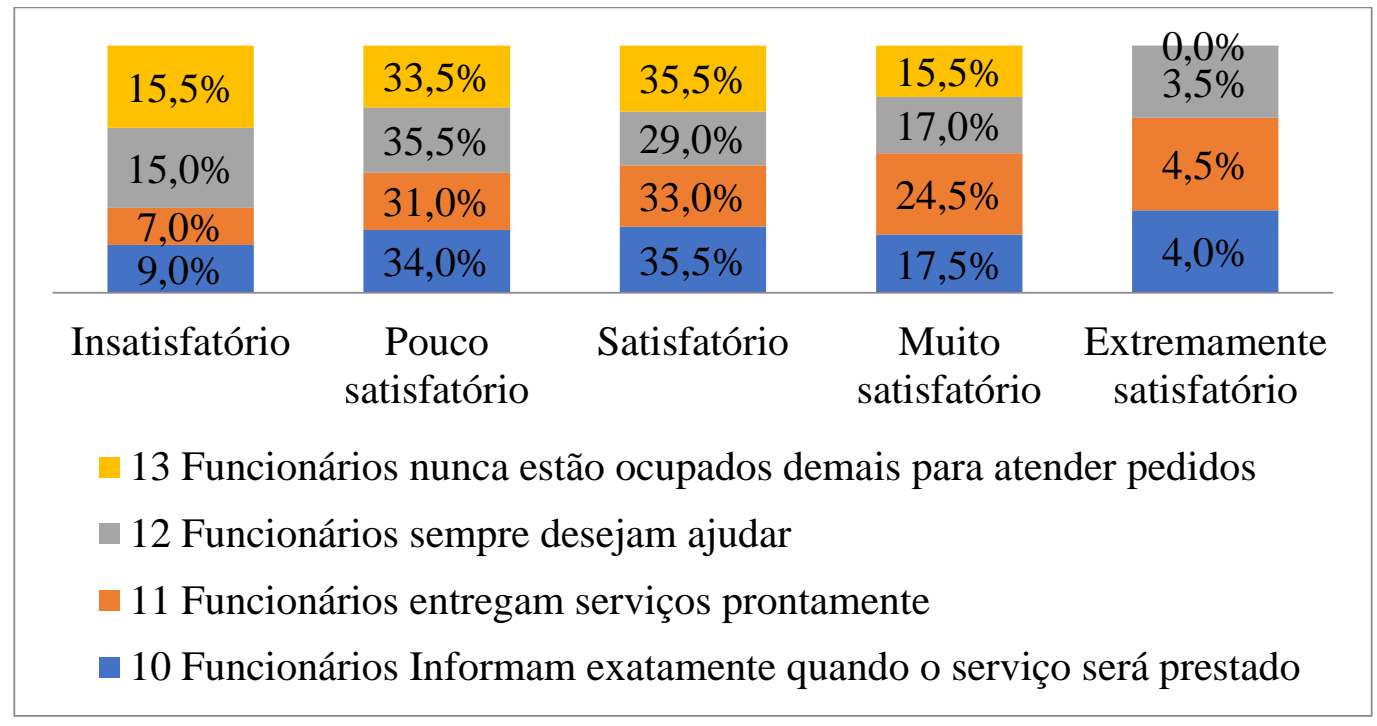

Fonte: Dados da pesquisa 2018

Por outro lado, é interessante perceber que os dados migram para o aspecto de insatisfação quando se fala em respostas ao que se espera, dado comprometido frente à utilização de materiais ou falta dos mesmos.

Gráfico 13: Garantia

\begin{tabular}{|c|c|c|c|c|}
\hline $5,5 \%$ & $20,0 \%$ & $42,0 \%$ & $25,5 \%$ & $7,0 \%$ \\
\hline $7,0 \%$ & $33.0 \%$ & $31,0 \%$ & $24,5 \%$ & $4,5 \%$ \\
\hline $10,0 \%$ & $13.5 \%$ & $43,5 \%$ & $26,5 \%$ & \\
\hline $8,0 \%$ & $20,0 \%$ & $35,5 \%$ & $23,5 \%$ & $13,0 \%$ \\
\hline Insatisfatório & $\begin{array}{c}\text { Pouco } \\
\text { satisfatório }\end{array}$ & Satisfatório & $\begin{array}{c}\text { Muito } \\
\text { satisfatório }\end{array}$ & $\begin{array}{l}\text { Extremamente } \\
\text { satisfatório }\end{array}$ \\
\hline \multicolumn{5}{|c|}{17 Funcionários têm conhecimento para responder as questões } \\
\hline \multicolumn{5}{|c|}{16 Funcionários são consistentemente corteses } \\
\hline \multicolumn{5}{|c|}{15 Clientes sentem-se seguros em suas transações } \\
\hline \multicolumn{5}{|c|}{ - 14 Comportamento dos funcionários inspira confiança } \\
\hline
\end{tabular}

Fonte: Dados da pesquisa (2018). 
Já no que se refere à garantia do serviço, observa-se certa fragilidade no tocante à abordagem das pessoas envolvidas em termos de comportamento e cortesia, destacando assim as capacitações e instalações no desempenho do serviço (BURMESTER, 2013).

Gráfico 14: Empatia

\begin{tabular}{|c|c|c|c|c|}
\hline $7,0 \%$ & $34,5 \%$ & $38,0 \%$ & 16,5 & $4,0 \%$ \\
\hline $13,5 \%$ & $30,0 \%$ & $41,0 \%$ & $11,0 \%$ & $\begin{array}{l}4,5 \% \\
5,0 \%\end{array}$ \\
\hline $4,5 \%$ & $35,5 \%$ & $38,0 \%$ & & \\
\hline $7,0 \%$ & $18,0 \%$ & $34,5 \%$ & $28,0 \%$ & $12,5 \%$ \\
\hline $11,0 \%$ & $40,0 \%$ & $26,5 \%$ & $19,0 \%$ & $5,3 \% 0$ \\
\hline Insatisfatório & $\begin{array}{c}\text { Pouco } \\
\text { satisfatório }\end{array}$ & Satisfatório & $\begin{array}{c}\text { Muito } \\
\text { satisfatório }\end{array}$ & $\begin{array}{l}\text { Extremamente } \\
\text { satisfatório }\end{array}$ \\
\hline \multicolumn{5}{|c|}{ - 22 Funcionários entendem as necessidades dos consumidores } \\
\hline \multicolumn{5}{|c|}{21 Têm verdadeiramente o melhor interesse nos clientes } \\
\hline \multicolumn{5}{|c|}{$\square 20$ Funcionários dão atenção pessoal } \\
\hline \multicolumn{5}{|c|}{19 Funciona em horários convenientes para todos os seus clientes } \\
\hline \multicolumn{5}{|c|}{ - 18 Fornece atenção individual ao cliente } \\
\hline
\end{tabular}

Fonte: Dados da pesquisa (2018).

Nos dados relacionados a empatia, a percepção também decresce, prevalescendo uma certa insatisfação, enfatizando os aspectos relativos à prestação de serviços (PALADINI, 2013; GIANESI; CORRÊA, 2012).

\section{Considerações Finais}

Dado o objetivo de analisar a percepção de usuários de serviços hospitalares de Juazeiro do Norte-CE, acerca da influência do gerenciamento dos estoques na qualidade da prestação de serviços, percebe-se fragilidades no tocante à falta de materiais e gerenciamento desses recursos para que não venham a influência na percepção de qualidade dos clientes.

Visto que as organizações que prestam serviços hospitalares à sociedade apresentam serviços muito relevantes, pois tratam de dificuldades diariamente, contudo detém aspectos onde há a necessidade de melhorias nos serviços apresentados, segundo as informações coletadas, como a atenção aos clientes, baixos níveis de cortesia pelos funcionários e desejo em ajudar, com atrasos nas atividades, assim gerando um serviço regular, podendo ocorrer complicações na gestão pela falta de recursos e pessoas. 
Percebe-se ainda que na qualidade do atendimento a gestão dos materiais e pessoas se mostra muito importante, pois melhora o nível dos serviços prestados e auxiliam nas atividades, entretanto deve se haver melhoria em características no atendimento a população em busca de reduzir ou minimizar as falhas citadas.

A relevância deste estudo mostra-se em acrescentar conhecimentos em relação ao gerenciamento dos materiais, nas aptidões dos serviços e elementos que influenciam a melhores tomadas de decisões. Porém se faz necessário a aplicação de ferramentas mencionadas ao logo do estudo para efetivação das práticas de gerenciamento, não incorrendo em custos desnecessários, tampouco comprometendo o nível de serviço ofertado e a satisfação do consumidor. Para pesquisas posteriores, sugere-se a aplicação de tais ferramentas, seja para a qualidade, como o ciclo PDCA, ou de recursos materiais.

\section{Referências}

BARBIERI, José Carlos.; MACHLINE, Claude. Logística hospitalar: teoria e prática. 3. ed. São Paulo: Saraiva, 2017.

BOWERSON, Donald J. [Et al.]. Gestão logística da cadeia de suprimentos. 4. Ed. Porto Alegre: AMGH, 2014.

BURMESTER, Haino. Gestão da qualidade hospitalar. 1. ed. São Paulo: Saraiva, 2013.

CARPINETTI, Luiz Cesar Ribeiro. Gestão da qualidade: conceitos e técnicas. 3. ed. São Paulo: Atlas, 2016.

CORONADO, Osmar. Logística integrada: modelo de gestão. 1. ed. São Paulo: Atlas, 2013.

CORREIA, Henrique Luiz. Administração de cadeias de suprimento e logística: o essencial São Paulo: Atlas, 2014.

DIAS, Marco Aurélio. Introdução à logística: fundamentos, práticas e integração. São Paulo: Atlas, 2017.

2012.

Administração de materiais: princípios, conceitos e gestão. 6. ed. São Paulo: Atlas,

GALVÃO, André Luiz Braun.; SILVA, Giszele Cristiane da. Serviços logísticos. 1. ed. São Paulo: Érica, 2014.

GIL, Antonio Carlos. Como elaborar projetos de pesquisa. 6.ed. São Paulo: Atlas, 2017.

GIANESI, Irineu G. N.; CORRÊA, Henrique Luiz. Administração estratégica de serviços: operações para a satisfação do cliente. 1. ed. São Paulo: Atlas, 2012. 
GONÇALVES, Paulo Sérgio. Logística e cadeia de suprimentos: o essencial. Barueri, São Paulo: Manole, 2013.

GRANT, David B. Gestão de logística e cadeia de suprimentos. 1. ed. São Paulo: Saraiva, 2013.

IBGE. População e Características Físicas de Juazeiro do Norte - Ceará. Disponível em: <https://cidades.ibge.gov.br/brasil/ce/juazeiro-do-norte/panorama>. Acesso em: 05 abr. 2018.

LAKATOS, Marina de Andrade.; MARCONI, Eva Maria, Lakatos. Fundamentos de metodologia científica. 8. ed. São Paulo: Atlas, 2017.

JURAN, Joseph M.; DeFEO, Joseph A. Fundamentos da qualidade para líderes. Porto Alegre: Bookman, 2015.

LAS CASAS, Alexandre Luzzi. Administração de marketing: conceitos, planejamento e aplicações à realidade brasileira. 1. ed. São Paulo: Atlas, 2012.

MENEZES, Vladenir.; OLIVEIRA, Sandra Figueiredo de (Org). Qualidade Total: Os pricipios do dr. Deming frente a realidade brasileira. 2. ed. São Paulo: Ixtlan, 2015.

MONTGOMERY, Douglas C. Introdução ao controle estatístico da qualidade. 7 . ed. Rio de Janeiro: LTC, 2017.

NOGUEIRA, Amarildo de Souza. Logística empresarial: um guia prático de operações logísticas. 2. ed. São Paulo: Atlas, 2018.

Logística empresarial: uma visão local com pensamento globalizado. 1.ed. São Paulo: Atlas, 2012.

NOVAES, Antônio Galvão. Logística e gerenciamento da cadeia de distribuição. 2. ed. Rio de Janeiro: Elsevier, 2004.

PALADINI, Edson Pacheco. Gestão da qualidade: teoria e prática. 3. ed. São Paulo: Atlas, 2012.

Edson Pacheco.; BRIDI, Eduardo. Gestão e avaliação da qualidade em serviços para organizações competitivas: estratégias básicas e o cliente misterioso. São Paulo: Atlas, 2013.

POZO, Hamilton. Administração de recursos materiais e patrimoniais: Uma abordagem logística. 7.ed. São Paulo: Atlas, 2015.

RENNÓ, Rodrigo. Administração geral para concursos. Rio de Janeiro: Elsevier, 2013

TOLEDO, José Carlos de. [Et al.]. Qualidade: gestão e métodos. Rio de Janeiro: LTC, 2017. 
ZEITHAML, Valarie A.; PARASURAMAN, A.; BERRY, Leonard L. A excelência em serviços: Como superar as expectativas e garantir a satisfação completa de seus clientes.1. ed. São Paulo: Saraiva, 2014.

\section{Como citar este artigo (Formato ABNT):}

SANTOS, Rafael Costa; OLIVEIRA, Alyne Leite de. Gestão de Estoques e sua Influência na Qualidade da Prestação de Serviços Hospitalares em Juazeiro do Norte-CE: Um Olhar do Público Atendido. Id on Line Rev.Mult. Psic., 2019, vol.13, n.43, p. 922-942. ISSN: 1981-1179.

Recebido: 01/12/2018;

Aceito: 03/12/2018 